\title{
LIFE SKILL TRAINING APPROACH TO UNDER TRIAL INIMATES: A STUDY OF FIELD WORK PRACTICE IN YERWADA CENTRAL PRISON, PUNE
}

\section{Dr. Prakash S. Yadav}

Assistant Professor \& Head, Department of SocialWork, Tilak Maharashtra Vidyapeeth, Gultekdi, Mukund Nagar, Pune, Maharashtra, India.

MSW II year student, Department of SocialWork, Tilak Maharashtra Vidyapeeth, Gultekdi, Mukund Nagar, Pune, Maharashtra, India. *Corresponding Author

\section{Introduction:}

Human beings need stability in their life. That is why they are trying to do such things to get that stability but got more and disturbance. There are such institutions are working on wellbeing and welfare of human being on international level. One of those is World Health Organization. It is established on $7^{\text {th }}$ April 1948. The main objective of the organization is to focus for getting the healthy lifestyle in perspectives of physical health, mental health and emotional health. Physical health can be accomplished by the health services such as Primary Health Center, Clinics or special medical campaign. But mental and emotional health cannot be fulfilled.

These are the some causes of getting instability or disturbance in life. We can also mention here the causes of criminal activities happening regularly. Thus Who Health Organization declared the basic ten life skills, can be useful for our daily routine life for our healthy, mental and emotional life.

\section{Concurrent Field Work}

Experimental approach in Fieldwork practicum: The fieldwork practicum needs to use the andragogical or the experimental approach. According to Johnson (1986), experimental learning is based on three assumptions,

i. People learn best when they are personally involved in the learning experience;

ii. Knowledge has to be discovered if it is to mean anything or make a difference in behavior; and

iii. Commitment to learning is highest when people are free to set their own learning goals and actively pursue them within a given framework.

Our department of social work, Tilak Maharashtra Vidyapeeth has tie up from academic year 2011-12, for concurrent field work to trainee social workers to explore and implement their theory practices learnt. In the concurrent field work, one rehabilitative group activity was conducted by trainee social worker. The main objective of the activity is to make awareness of core life skills among lounder trial prison inmates with special reference to Yerawada Central Prison, Pune. The social work department of Tilak Maharashtra Vidyapeeth, the prison department of western zone of Maharashtra, faculty supervisor and trainee social worker frame a well planned group work activities according to the principles of group work.

\section{Yerawada Central Prison at a Glance:}

Yerawada Central Prison is one the oldest and largest prison in india. It was established in 1871 during British Empire. There are more than 4000 inmates in the prison divided into main six yards. The number of inmates is probably more than the capacity of the prison. Hospital yard with 3 sections is one the main yard among six yards. One of section from hospital yard is called 'Kishor Vibhag' where the under trials keep with the age group of $18 \mathrm{yrs}$. to 2 lyrs. There are more than 300 inmates daily. The number is varied everyday due to bail-out, bail-in or arresting.

But there were some limitations while interacting with inmates. As we know prison is one the most sensitive setting in society, that's why prison administration made some restrictions for group work. They provided one police personnel for the security purpose. Thus the group work has begun with 10 inmates from various background, geographical area and criminal records. Prison administration had given a group of people who were calm in their regular behavior. It was supposed to be good while working and interacting with them.

In first session, trainee social worker introduced himself and made him known to everyone and vise-a-versa. While interacting with them, he observed the pattern of talking and behavior that he could utilize a supportive group in group activities. The only objective of the session was to make them speak up. Everyone was in progress in speaking frankly that made session more interactive. According to planning the group activities were conducted twice in week.

\section{SocialWork Education and Life Skills:}

Fieldwork is the most essential part of the social work education and training. Taking an overview of the present situation of the fieldwork training, its nature, scope, professionalization, problems and difficulties and the needs, it may be observed that the universities and the colleges of social work lack something in imparting comprehensive field *work training to the students.

In the field work training itself, there are certain deficiencies and shortcomings. The most important aspect are the policies of the universities and the colleges of social work whereby the theoretical and practical curriculum are formulated and arrangements are made for imparting education and training according to the prescribed curricula. But till today ways of field work have been used by the most of social work schools. In which the agency based field work is carried out. But there is need of some community based trends in field work training in social work education.

Fieldwork practicum is a closely supervised educational internship in a social work setting that provides planned opportunities to apply theory taught in class-work to actual situations, which, in turn, enhances classroom learning. Learning and practice of social work methods and skills of work with individuals and the socio-economic-political systems of family, community, state, corporate sector, mass media and non-profit organizations, democratize them, drawing linkages across them, to prevent and ameliorate social problems; and documentation, monitoring and evaluation of one's social work intervention.

The ten core life skills as laid down by World Health Organization: 


\author{
1.Self Awareness \\ 2.Empathy \\ 3. Critical Thinking \\ 4. Creative Thinking \\ 5.Decision Making \\ 6.Problem Solving \\ 7.Effective Communication \\ 8. Interpersonal Relationship \\ 9. Coping with Stress \\ 10. Coping with emotion
}

\section{Life Skills at a Glance:}

1. Self Awareness - to know self, a simple skill to be clear about self.

2. Empathy - to understand what other feels, an ability to experience one's life in the one's perspective.

3. Critical thinking - to convert experience into right conclusion, to analyze data we experience.

4. Creative thinking - a skill to create new ideas related to simplify the life or make more exquisite.

5. Decision making - human being must have to decide in situation of 'to be or not to be', an ability to choose right option.

6. Problem solving - problem is a part of human life. Thus, that is an ability to be neutral in such circumstances to tackle the problem is problem solving.

7. Effective communication - to have an ability to express their thoughts in effective manner is called as an effective communication.

8. Interpersonal relationship - to make positive relations with people while interacting. It may also able to create relationships constructively.

9. Coping with stress - a skill to identify situations affecting to the environment of lives and which create stress in those circumstances.

10. Coping with emotions - to control the emotions, an abikity to give response to emotions appropriately.

Above mentioned all life skills are to be made effective life style of common human being, but in absence of these skills such circumstances has been made in life those are not expected from own family, community and society. Those unexpected behaviors turn out to be crime in perspective of law and order and judicial.

These people are placed in custody or in a prison to make positive changes or sublime their lives. It can be called as correction, enhancement, improvement, optimization or reformation etc. The vision of Maharashtra State Prison Department is 'सुधारणा आणि पुनर्वसन'. That means 'Enhancement and Rehabilitation'. The state prison department is applying and implementing programs related to the vision.

\section{Methodology Adopted:}

Participatory Methodology:

In the participatory methodology, it is assumed that knowledge and education are never neutral and the trainer's role is help to the participants understand where their own views have come from, to challenge pre-conceptions and to encourage them to consider other possibilities. It assumes that society can be transformed by the engagement of critically conscious persons, through a process of deconstruction, reconstruction and transformation. Participants' life experiences are the major source of knowledge in this method. The trainers are not teachers, but facilitators, and partners with the participants in this process of social change.

\section{Need Analysis:}

While studying the plan of action of practice, it is essential to ascertain that it is based on the actual and felt needs of the potential beneficiaries, depending up on their situation. Such baseline data is obtained through need analysis. Some objective criteria, to establish the need conditions for the specific intervention, will first have to be theoretically worked out, based on the expected outcome. All the individuals in an age group may need developmental intervention, where as specific outcome have to be laid down for need for remedial intervention. According to Carter (1960), the need conditions may be those expressed by clients and those unexpressed by clients. For the needs expressed by the clients, they may not be utilizing the services.

\section{A need analysis used in three major ways:}

i. The scope of the programme planned according to the magnitude of people concluded as the needing the intervention.

ii. The characteristics of the people needing the intervention can be useful while planning the content of the intervention. iii. The difficulties people report in utilizing services of similar programmes are useful for planning the service delivery aspects of practice.

\section{GroupWork Practice inYCP: \\ Objectives:}

1. To give a glance of 10 life skills laid down by World Health Organization among inmates (age 18-21) from Kishor Vibhag, Yerwada Central Prison, Pune

2. To make them understand to implement life skills in own life.

3. To reduce a communication gap between stakeholders and inmates.

4. To make them more actively participative in rehabilitative activities conducted by prison administration.

\section{Process followed}

\section{a) Initial Stage}

In first session, trainee social worker introduced himself and made him known to everyone and vise-a-versa. While interacting with them, he observed the pattern of talking and behavior that he could utilize a supportive group in group activities. The only objective of the session was to make them speak up. Everyone was in progress in speaking frankly that made session more interactive. According to planning the group activities were conducted twice in week.

The second session was based upon introduction of hobbies, interests, telling things that they like to do. That was brain game. Remembering the names told previous by their colleagues and add their own names. The object of the activity is to define how attentive they were while session was going and another object to their memory power. It helped trainee social worker to understand each and everyone. It also created positive group dynamics in the group. Rapport was being established during these sessions.

The third session was pre-introduction of life skills, healthy lifestyles-

\section{Phyical health 2.Mental health 3.Emotional health} Trainee social worker had made debatable topic on these sub-points and made them to relate how disturbed mental and emotional health create complications, obstacles in routine life. Inmates shared their stories about complications done by them. They convinced that changes had happened in their lives due to those reasons. There are some key issues in this period of life.
1.Developing an identity
2.Managing emotions
3. Building relationships
4. Resisting peer pressure
5. Acquiring information, education

These were the focus points of the session. 


\begin{abstract}
b) Middle Phase
After the introductory session, the life skill program had been started with those inmates. First session had covered three life skills. Second and third session had also covered another remained seven life skills. The sessions were mainly focused on discussions, experiences sharing, storytelling, indoor games, brain-storming activities, debates. The sessions were organized in such manner that inmates could think upon ideas what discussed and apply to their lives. In every session, trainee social worker had kept 15 minutes for discussion how they could apply these skills. Thus the core activity of the group had completed.
\end{abstract}

\title{
c) Termination Phase
}

In the last session, all the inmates discussed upon all experience of sessions, what problem they had faced, what ideas they got to learn.

\section{Outcomes:}

1. Inmates started to discuss ideas, problems, and experiences with the stakeholders of prison administration and police personnel.

2. They received an opportunity to express their views and thoughts thus they become more interactive with others.

3. Group members started to participate in rehabilitative activities conducted by prison e.g. 10 out of 10 has actively participated in 'Air Conditioner/ Fridge repairing training program' which is going on these days in Yerwada Central Prison'.

4. The communication distance between inmates and stakeholders has started reducing on the level of various training programs. ' 10 inmates' is very small number but it was just beginning. It is an experimental based.

5. Two police personnel had shared their views on changed pattern of behavior of inmates in some of areas but not in all.

\section{Conclusion:}

It was too much sensitive work with those inmates. There were some boundaries to communicate, limitations of resources. The inmates had carried out the Burdon of police personnel's in prison. But according to one of social work principle 'hate the crime, not to criminal', it was concluded to trainee social worker that curative work can be done with inmates those who are under trial. It becomes more constructive not only for their rehabilitation but also for re-integration in the society.

Acknowledgement: Authors are generally acknowledged the support extended by YCP, Pune, office bearers from YCP. Pune.

\section{References:}

1. Chakrabarti N. K. Institutional Corrections, in the Administration for Criminal Justice System, Deep \& Deep Publications.

2. Dr.I.S.Subhedar, Indigenous FieldWork, Rawat Publication, New Delhi

3. Dr. B. T. Lawani, South Asian Journal of Participative Development, YashwantraoChavan Social Science Centre, BharatiVidyapeeth, Pune.

4. Introduction to Life Skills for Psycho-social Competence, WHO/MNH/PSF/93.7A

5. Murali Desai, SocialWork Education in India, Rawat Publications, New Delhi.

6. www.who.org.in

7. www.lifeskills.in 